\title{
Comment on "Paraneoplastic encephalomyelitis revealing burned-out seminoma": confirmed case of anti-Kelch-like protein-11 encephalomyelitis
}

\author{
Sofia Maldonado Slootjes ${ }^{1,2} \cdot$ Jon Landa ${ }^{3} \cdot$ Lidia Sabater $^{3} \cdot$ Vincent van Pesch $^{1}$ (1)
}

Received: 12 September 2021 / Accepted: 16 September 2021 / Published online: 15 October 2021

(c) Belgian Neurological Society 2021

Keywords Paraneoplastic neurological syndrome $\cdot$ Encephalomyelitis $\cdot$ Burned-out seminoma $\cdot$ Kelch-like protein-11

Paraneoplastic neurological syndromes occur in association with cancer and have an immune-mediated pathogenesis, but sometimes neuronal antibodies cannot be identified. Recently, Guilmot et al. [1] published a Letter to the Editor describing a case of paraneoplastic encephalomyelitis that led to the diagnosis of a burned-out seminoma, but the patient remained seronegative for all the onconeuronal antibodies known at that time. The 52-year-old patient presented with hearing loss, vertigo, diplopia, nystagmus, and ataxia, and later developed gait difficulties, limb incoordination, and left arm weakness. Repeated brain magnetic resonance imaging (MRI) revealed T2/FLAIR hyperintensities in both thalami, brainstem, and right temporal lobe, while spinal cord imaging showed an extensive myelitis. Cerebrospinal fluid (CSF) studies showed lymphocytic pleocytosis, elevated protein levels, and CSF-specific IgG oligoclonal bands. Given the suspicion of a paraneoplastic syndrome, an extensive workup was performed and revealed a para-aortic nodal metastasis of a burned-out seminoma. Despite orchiectomy, radiotherapy, and multiples lines of immunotherapy, the patient died 16 months after symptom onset.

Kelch-Like Family Member 11 (KLHL11) is an intra-cellular protein involved in ubiquitination [2]. Autoantibodies

Vincent van Pesch

vincent.vanpesch@saintluc.uclouvain.be

1 Department of Neurology, Cliniques Universitaires SaintLuc, UCLouvain, Avenue Hippocrate 10, 1200 Brussels, Belgium

2 Department of Neurology, Vrije Universiteit Brussel (VUB), Universitair Ziekenhuis Brussel (UZ Brussel), Laarbeeklaan 101, 1090 Brussels, Belgium

3 Institut d'Investigacions Biomèdiques August Pi I Sunyer (IDIBAPS), Neuroimmunology Program, Universitat de Barcelona, Barcelona, Spain against KLHL11 (anti-KLHL11-Ab) were first identified in 13 patients with seminoma, most of whom presented with rhombencephalitis, in the absence of anti-Ma2 autoantibodies [2], but recent studies have widened the clinical spectrum, shedding new light on Guilmot et al.'s report [3-5].

Based on Dubey et al.'s recent cohort study, the predominant clinical symptoms of this entity consist of ataxia, diplopia, dysarthria, vertigo, hearing loss, and tinnitus. These two last symptoms may precede other manifestations and are considered distinguishing features of anti-KLHL11 encephalitis [2,3]. Anti-KLHL11 autoimmunity may also present as limbic encephalitis, transverse myelitis with polyradiculoneuropathy, or opsoclonus-myoclonus syndrome, and may include subacute encephalopathy, upper limb weakness, cervical amyotrophy, and trigeminal neuralgia [3, 4]. Besides seminoma (which may involve an extratesticular location or a burned-out tumor), it has been associated with benign teratoma, mixed germ cell tumors, ovarian cancer, smallcell lung cancer, lung adenocarcinoma, and chronic lymphocytic leukemia [3, 4]. Brain MRI may reveal T2/FLAIR hyperintensity in the temporal lobe, cerebellum, brainstem, diencephalon, and/or spinal cord [3]. CSF often shows pleocytosis and/or presence of CSF-specific IgG oligoclonal bands [3]. Anti-KLHL11 autoimmunity is thought to be T-cell-mediated and may in some cases concur with other onconeural antibodies such as anti-NMDAR, anti-Ma2, or anti-Hu antibodies [3-5]. Anti-KLHL11 encephalitis seems to be associated with poor prognosis, as it is often refractory to treatment [3].

The striking similarities between Guilmot et al.'s patient and recent literature lead us to posthumously test for antiKLHL11-Abs in the reported patient, with the consent of the patient's next-of-kin. Titration using a cell-based assay revealed the presence of anti-KLHL11-Abs in both serum 
Fig. 1 Cell-based assay with HEK293 cells expressing human KLHL11. A Reactivity (green) of the CSF of the patient $1 / 8000$ diluted. No immunoreactivity is observed with a control CSF (D). Reactivity in (B) and (E) (red) corresponds to a commercial KLHL11-ab. $\mathbf{C}$ and $\mathbf{F}$ Merged reactivities of the indicated patients (patient and control samples) with the commercial KLHL11-ab, shows a perfect colocalization only with patients' antibodies. Scale bar $=20 \mu \mathrm{m}$
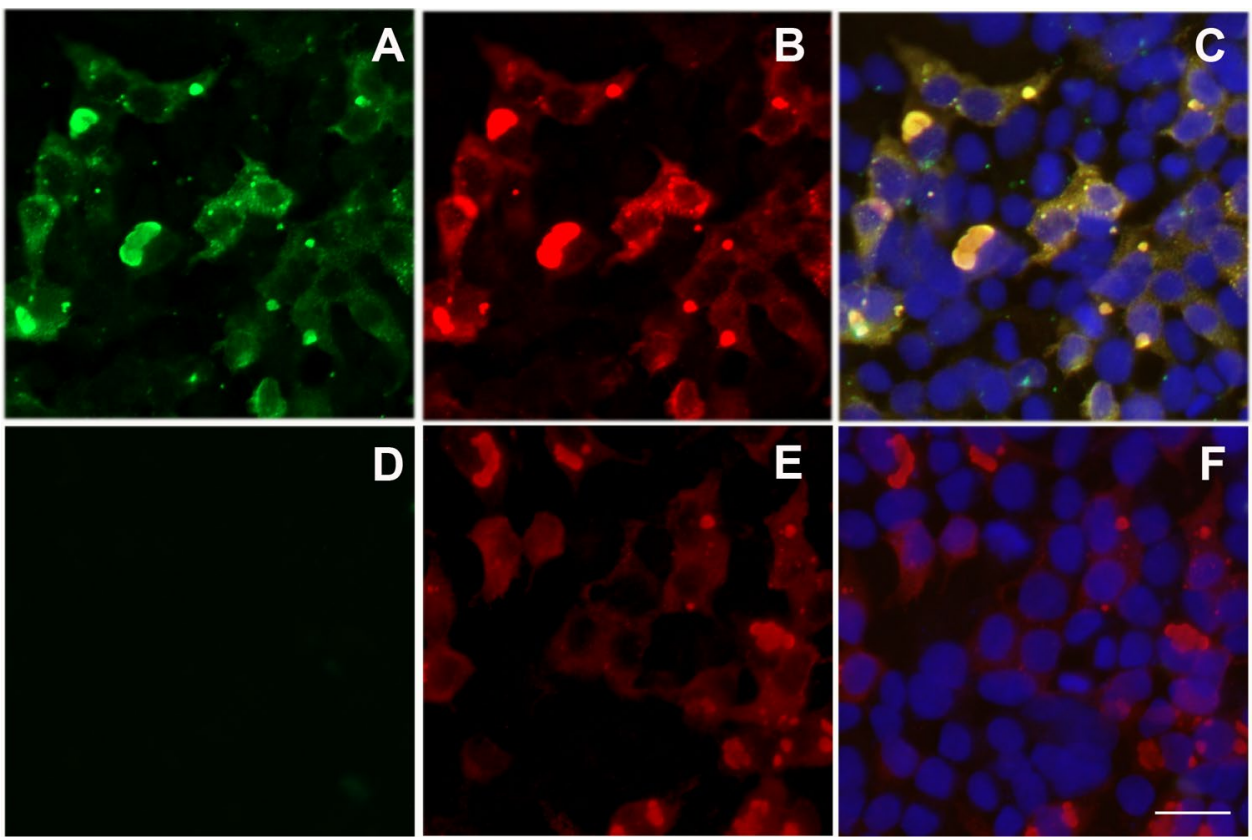

and CSF, at titers above $1 / 80,000$ and $1 / 8000$, respectively (Fig. 1).

In conclusion, this comment retrospectively identifies a case of anti-Kelch-like protein-11 encephalomyelitis, in the aim to raise awareness for anti-KLHL11-associated paraneoplastic syndromes. This novel entity should primarily be suspected in anti-Ma2 antibody-negative patients with rhombencephalitis, especially in the presence of vestibular symptoms and/or in association with a testicular tumor.

Acknowledgements The authors wish to thank Dr. Ludovic d'Auria and Ms. María Rodes for their technical support, as well as Dr. Antoine Guilmot, Prof. Thierry Duprez, and Dr. Philippe Jacquerye, who authored the original report.

Author contributions Study concept and design: SMS. Acquisition of data: SMS and VvP. Analysis and interpretation of data: JL and LS. Drafting of the manuscript: SMS. Critical revision of the manuscript: all authors. Study supervision: VvP. All authors read and approved the final manuscript.

\section{Funding None.}

Availability of data and materials Not applicable.

Code availability Not applicable.

\section{Declarations}

Conflicts of interest The authors declare that they have no conflict of interest.

Ethics approval Not applicable.
Consent to participate Not applicable.

Consent for publication Not applicable.

\section{References}

1. Guilmot A, van Pesch V, Duprez T, Jacquerye P (2020) Paraneoplastic encephalomyelitis revealing burned-out seminoma. Acta Neurol Belg. https://doi.org/10.1007/s13760-020-01447-7

2. Mandel-Brehm C, Dubey D, Kryzer TJ, O’Donovan BD, Tran B, Vazquez SE, Sample HA, Zorn KC, Khan LM, Bledsoe IO, McKeon A, Pleasure SJ, Lennon VA, DeRisi JL, Wilson MR, Pittock SJ (2019) Kelch-like protein 11 antibodies in seminomaassociated paraneoplastic encephalitis. N Engl J Med 381(1):4754. https://doi.org/10.1056/NEJMoa1816721

3. Dubey D, Wilson MR, Clarkson B, Giannini C, Gandhi M, Cheville J, Lennon VA, Eggers S, Devine MF, Mandel-Brehm C, Kryzer T, Hinson SR, Khazaie K, Hales C, Kattah J, Pavelko KD, Andrews P, Eaton JE, Jitprapaikulsan J, Mills JR, Flanagan EP, Zekeridou A, Leibovich B, Fryer J, Torre M, Kaufman C, Thoreson JB, Sagen J, Linnoila JJ, DeRisi JL, Howe CL, McKeon A, Pittock SJ (2020) Expanded clinical phenotype, oncological associations, and immunopathologic insights of paraneoplastic Kelch-like protein-11 encephalitis. JAMA Neurol 77(11):1420-1429. https://doi.org/10.1001/jamaneurol.2020.2231

4. Maudes E, Landa J, Muñoz-Lopetegi A, Armangue T, Alba M, Saiz A, Graus F, Dalmau J, Sabater L (2020) Clinical significance of Kelch-like protein 11 antibodies. Neurol Neuroimmunol Neuroinflamm 7:e666. https://doi.org/10.1212/NXI.0000000000000666

5. Vogrig A, Péricart S, Pinto A-L, Rogemond V, Muñiz-Castrillo S, Picard G, Selton M, Mittelbronn M, MD, Lanoiselée H-M, Michenet P, Benaiteau M, Pariente J, Zéphir H, Giordana C, Montaut S, Salhi $\mathrm{H}$, Bachoumas P, Montcuquet A, Letovanec I, Uro-Coste E, Honnorat J (2021) Immunopathogenesis and proposed clinical score for identifiying Kelch-Like Protein-11 encephalitis. Brain Commun 3(3):fcab185. https://doi.org/10.1093/braincomms/fcab185

Publisher's Note Springer Nature remains neutral with regard to jurisdictional claims in published maps and institutional affiliations. 